\title{
Establishment, Description and Equivalence of Flax Fabric Reinforced and E-Glass Fabric Reinforced Polyester Based Composite
}

\author{
A.K.Arun Raja, B.Suresh, Shobhan kumar, G.Priyadharshan, K.Arun Vasantha Geethan
}

\begin{abstract}
Every fabric can be categorized as either synthetic or natural fibre. Both natural and synthetic fibre have both advantages and disadvantages. Natural fibres are extracted from various plants and animals' sources, while synthetic fibres are made from chemical compounds which requires enormous amount of non- renewable energy sources. Comparing with the flax fabric, glass fibre mats are made from silica (SiO2) sand, which melts at $1720^{\circ} \mathrm{C} / 3128^{\circ} \mathrm{F}$. Glass fibre mat requires burning enormous of fossil fuel for producing heat, whereas flax fabric is extracted from the bast or the skin of linseed plant that grow inside stalks of the plants. Flax fabric is hydrophilic in nature, which by the mercerization process is converted to hydrophobic in nature. In Mercerization process fabric is treated with a caustic soda $(\mathrm{NaOH})$ solution in water to improve properties such as fibre strength, shrink-age resistance, lustre, and dye affinity. The composites manufacturing process known as Hand layup involves laying down individual reinforced fabric of glass and flax separately and then wet with isophthalic resin (mixed with $2 \%$ of charcoal) by measuring the quantity by weighing. Scanning Electron Microscopy (SEM) analysis, provides evaluating of glass and flax reinforced composites for surface fractures, flaws, contaminants or corrosion. In order to check the flame resistance fire retardant test is done. Furthermore, mechanical test result showed the comparative values of tensile, impact and flexural strength of both the composites.
\end{abstract}

Keywords: Glass fabric, Flax fabric, Mercerization, Hand layup, SEM.

\section{INTRODUCTION:}

As there's steep rise in the population in the recent years on the planet, we face multitude environmental problems [1]. The increase in environmental concerns in the recent years, the new environmental regulations have led us to the use of eco benevolent material. Natural fibres are viewed as one of the most eco benevolent materials having great properties when compared to synthetic fibre [2].

Revised Manuscript Received on September 25, 2020.

* Correspondence Author

Mr. A. K. Arun Raja*, Assistant Professor, Mechanical Engineering Department, St. Joseph's Institute of Technology, OMR, Chennai, Tamil Nadu, India.

Mr. B. Suresh, Mechanical Engineering, St. Joseph's Institute of Technology, OMR, Chennai, Tamil Nadu, India.

Mr. Shobhan Kumar, Mechanical Engineering, St. Joseph's Institute of Technology, OMR, Chennai, Tamil Nadu, India.

Mr. G. Priyadharshan, Mechanical Engineering, St. Joseph's Institute of Technology, OMR, Chennai, Tamil Nadu, India.

Dr. K. Arun Vasantha Geethan, Professor and Head of the Department of Mechanical Engineering, St. Joseph's Institute of Technology, OMR, Chennai, Chennai, Tamil Nadu, India.

(c) The Authors. Published by Blue Eyes Intelligence Engineering and Sciences Publication (BEIESP). This is an open access article under the CC BY-NC-ND license (http://creativecommons.org/licenses/by-nc-nd/4.0/)
For the past 2 decades the interest in the NFC is growing rapidly for several reasons as they have the potential to replace synthetic fibres at a lower cost and with improved sustainability [3]. The use of NFC has interested many in applications ranging from athletic gear, aerospace, automotive applications etc. The main driving principle for the use of the NFC in day to day life is because of its ecology concern as they are recyclable and environmentally friendly [4].The sources from which natural fibres acquired are vegetation and animals. Additionally, extraction of natural fibre is from finite resources like oil palm, flax and jute. The principle focus is to create composite materials.[5]. In the present-day studies, the fibres like jute, flax, kenaf and banana have been playing the significant role in the place of replacing the conventional fibres like glass fibre, carbon fibre and of all spots of synthetic fibres [6].These fibres are used because they offer low carbon footprint and biodegradability advantages combined with high specific quality and stiffness at an affordable price [7].Specific mechanical properties of the materials that uses high quality fibres accomplished much better qualities than composites reinforced by man. For example, flax is very strong natural fibre with a tensile strength of 1.5 GPaand a particular tensile strength of $\mathrm{GPa} \cdot \mathrm{m} 3 \cdot \mathrm{kg}-1$. Because of these properties and their sustainability, flax fibres are viewed as an eco-friendlyalternative to glass fibres for use in composites. These fibres have various different advantages contrasted with glass, basalt or carbon fibres: they don't cause skin disturbance, their edges blunt less, they do an excellent job of absorbing energy, vibration and UV radiation, they don't make static charge, they are resistant to bugs and microscopic organisms, they are harmless to human, they are biodegradable and they don't release VOCs. Combined with low density and high strength, they are intended for material use in composites. Then again, their disadvantages are degradation at lower temperatures, higher variability of mechanical properties, lower maximum tensile strength and lower relative elongation.[8] The main aim of our work is to develop an eco-friendly, economical and valuable composites. That ought to have great properties and find lots of applications in present day life.

\section{MATERIALS:}

\section{A. Flax fabric:}

One of the oldest cultivated plants in human history is Flax (Linumusitatissimum), also known as linseed. Flaxfibres vary in length from about 25 to $150 \mathrm{~mm}$

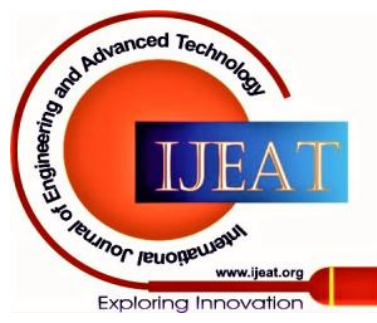

Blue Eyes Intelligence Engineering and Sciences Publication (C) Convriaht: All riahts reserved. 


\section{Establishment, Description and Equivalence of Flax Fabric Reinforced and E-Glass Fabric Reinforced Polyester Based Composite}

(1 to 6 inches) and average 12-16 micrometers in diameter. There are two varieties: shorter tow fibres used for coarser fabrics and longer line fibres used for finer fabrics. Flax fibres can usually be identified by their "nodes" which add to the flexibility and texture of the fabric.

- Flax Fibre Manufacturing Processes:

Flax fabric is made from the cellulose fibres that grow inside stalks of the flax plant. For fibre production flax is harvested about 100 days, after a month if the plants are still green, the fibre is underdeveloped.

The fibre degrades once the plants turn brown.To harvest flax fibre two ways are used, one is mechanized equipment and a second method is manual.

- Physical properties of Flax fibres:

Color - yellowish to gray

Length -18 to 30 inches

Tensile strength - tenacity of 5.5 to 6.5 gms/den.

Elongation at a break -2.7 to $3.5 \%$

Specific gravity -1.54

Moisture regain -10 to $12 \%$.

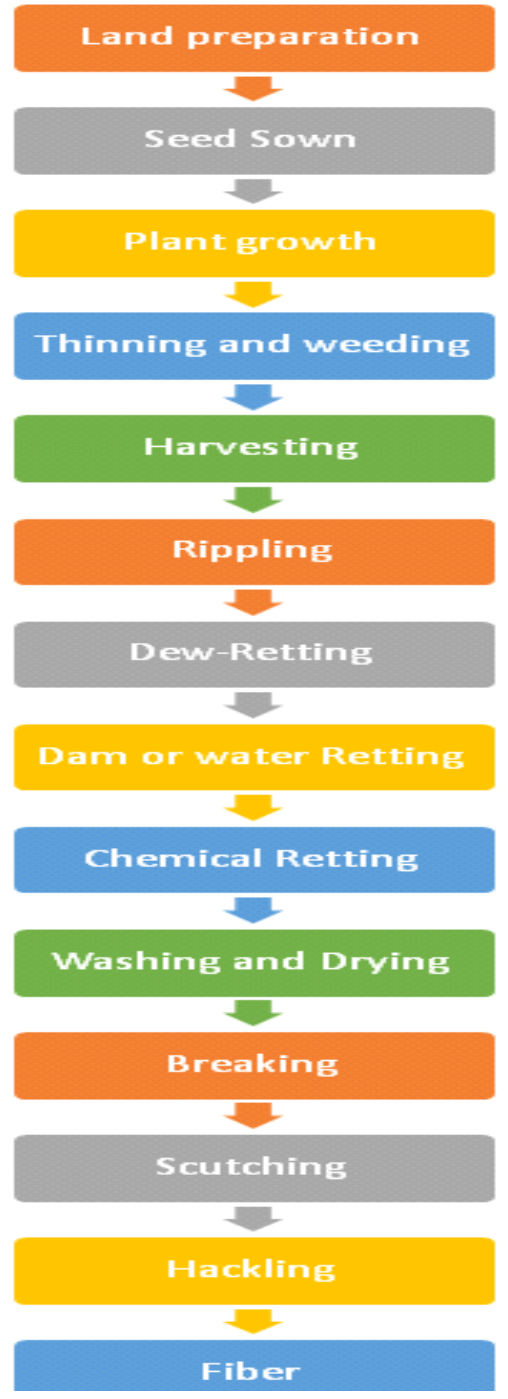

Fig.1. Flowchart of Flax Production.

- Characteristics of Flax Fabrics:

Linen Fibre is stronger than Cotton: Another reason behind of the linen fibre popularity is - you will get the same comfort like Cotton in the Linen fibre but the strength of the Linen fibre is twice than the Cotton fibre. In sportswear where the strength is a matter, there the Linen fibre is widely used.
Crisp feeling: If you touch the linen fibre, you will feel that it's a simply crisp fibre which has distinctive outlook and feels.

Lightweight to Heavyweight: Any kind of linen fabric or linen fibres are available on the market which can be achieved in any weight as per the Textile buyers' requirement.

No Static \& Pilling problems: If any fabric produces the static electricity during wear, then nothing can be worse than that Linen is the perfect fabric in this regard which has no static electricity and pilling problems.

Good Abrasion Resistant: As the linen fibre is good in strength, then it is supposed to have the properties like Good abrasion resistant.

\section{B. Glass Fabric:}

Glass is also called Fiberglass which is much older composite. Fibres have been manufactured from glass since the 1930s.Glass is the oldest, and most performance fibre.Compared to metals glass fabric has bulk strength, lightweight, and robust material. Glassfibre is known for its ability to get moulded into various complex shapes.

- Glass Fibre Manufacturing Processes:

Glass fibre is made by coalescing raw materials, melting them in a three-stage furnace, extruding the molten glass through a bushing in the bottom of the fore hearth, cooling the filaments with water and then applying a chemical size. The gathered filaments are wound into a package.

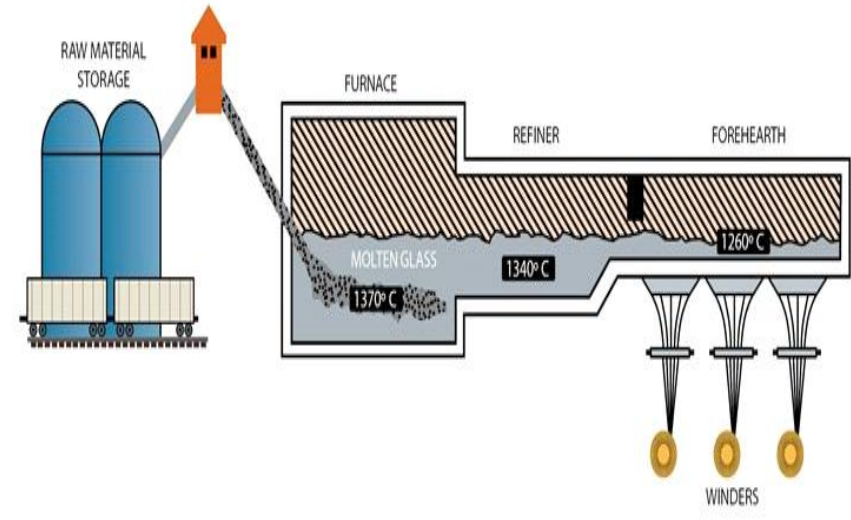

Fig.2. Manufacturing of Glass fibre

The production process can be divided into five basic stages-Blend, Melting, Fiberization, Covering, Drying / Packing.

- Types of Glass Fibre:

A-glass: Also called as alkali glass and is resistant to chemicals.

C-glass: Also called as chemical glass and offers very good resistance to chemical impact.

E-glass: Also called as electrical glass and very good insulator of electricity.

AE-glass: Alkali resistant glass.

S glass: Also called as structural glass and known for its mechanical properties.

- Properties of fiberglass:

Published By:

Blue Eyes Intelligence Engineering

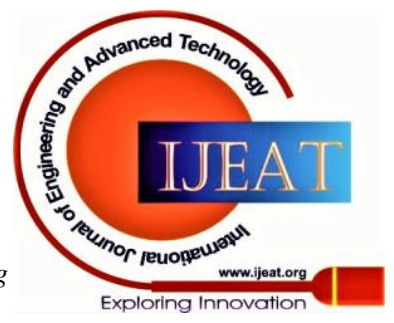




\section{Establishment, Description and Equivalence of Flax Fabric Reinforced and E-Glass Fabric Reinforced Polyester Based Composite}

Mechanical strength: Fiberglass has a specific resistance greater than steel. So, it is used to make high-performance Non-rotting: Fiberglass does not rot and remains unaffected by the action of rodents and insects.

Thermal conductivity: Fiberglass has low thermal conductivity making it highly useful in the building industry. Dielectric permeability: This property of fiberglass makes it suitable for electromagnetic windows.

- Applications of Fiberglass in various Industries: Beverage industry, Car washes, Chemical industry, Cooling towers, Docks and marinas, Food processing, Fountains and aquariums, Manufacturing, Metals and mining, Power generation, Plating plants, Pulp and paper industry, Automotive industry, Aerospace \& Defense.

\section{Isophthalic resin:}

Isophthalic is a thixotropic, high strength, low-viscosity, polyester resin with excellent heat and chemical resistance. It is corrosion, temperature, solvent, and fuel resistant. All resins must be catalyzed with catalyst or hardener before use for chemical reaction tostart turning the resin from a liquid to a solid, un-catalyzed resin simply will not harden. Isophthalic resin is catalysed with 5\% of MEKP DDM-9 Methyl Ethyl Ketone Peroxide Hardener Catalyst.

- Properties of Isophthalic resin:

Adequate resistance to water and variety chemicals.

Adequate resistance to weathering and ageing.

Withstand a temperature up to $80^{\circ} \mathrm{C}$.

Good wetting to glass fibres.

Low shrinkage $4-8 \%$ during curing.

D.

\section{EXPERIMENTAL PROCEDURE:}

All plant based natural fabrics are hydrophilic in nature. Hydrophilic fabrics absorb moisture and elongate. These fabrics may become unstable and sink or ruffles when the humidity reaches $44 \%$. Plant based natural fibres such as wool, cotton and flax, may return to normal size and form when humidity levels drop. When a fabric isn't stable, stretched vertical application is difficult. While Hydrophobic fibres such as polyester, acrylic and non-acrylic, have poor absorbent. Therefore this fabric remains stable. In fact, synthetic fibres are suitable for stretched applications, but we can't use synthetic fibres incessantly.In order to overcome the drawback in natural fabrics, the fabrics are converted into hydrophobic in nature, for that Mercerization process i.e. Fabric treatment is used. In Mercerization process the flax fabric matt is treated with caustic NAOH (Sodium hydroxide) for 7hours at ambient temperature. Subsequently, the flax fabric matt is dried for 24hours. After mercerization process the fabric has Ameliorated lustre, High ability to absorb dye, Improved reactions with a variety of chemicals, High stability of form, Enhanced strength/elongation and Better smoothness.

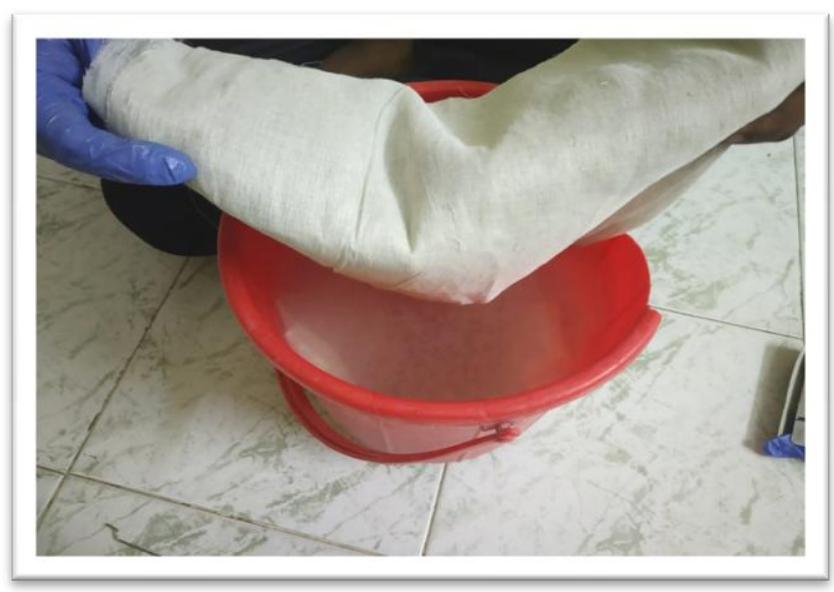

Fig.3. Flax Fabric Mercerization Process

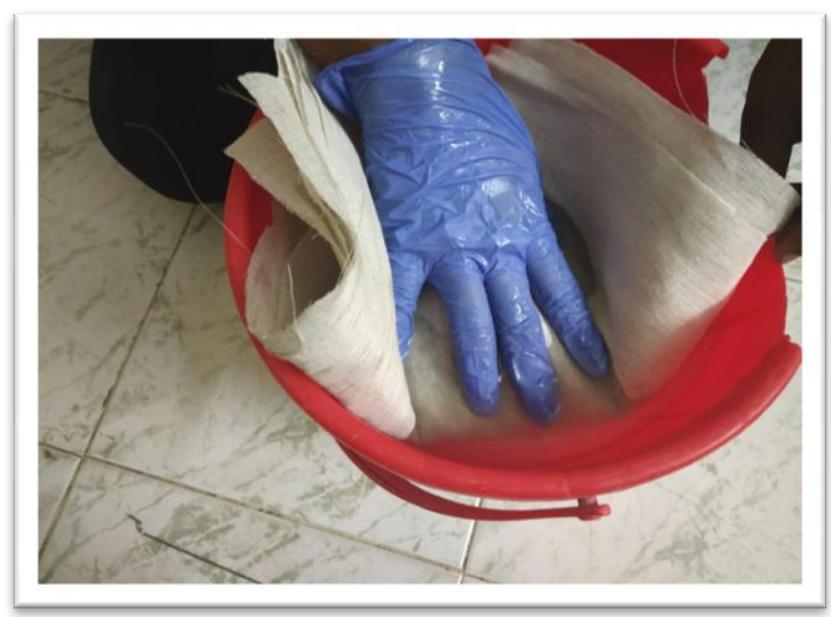

Fig.4. Flax Fabric Mercerization Process

E. Hand lay-up:

Some common Composite fabrication methods are Hand lay-up, Resin Infusion Methods, Compression Moulding, Injection Moulding. The plenteous number of composite products are produced by the hand lay-up process. Hand lay-up is an open moulding method for making composites products. The fundamental concept used incomposites is the combination of matrix and a reinforcement fabric to make a new material.In hand-layup process the reinforced flax fabric matt and glass fibre are placed separately, treated with isophthalic resin at room temperature by measuring the quantity by weighing and the filler charcoal powder is mixed with the resin. For polymerization process the catalyst and hardener (5\% of MEKP DDM-9) is added with resin. The charcoal powder is used to reduce the net weight. After the resin is mixed with catalyst and filler is applied to fabric by pouring and brushing. Layup is made by building the layer upon layer to obtain the desired thickness. Thereupon the composites are dried for 2hours. The weight ratio is Fabric: Resin: Filler::20:78:2.

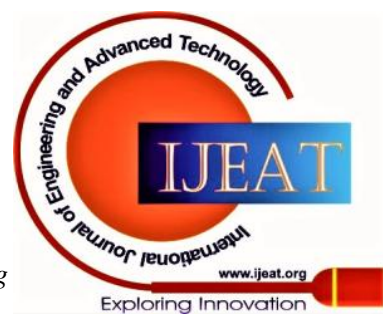




\section{Establishment, Description and Equivalence of Flax Fabric Reinforced and E-Glass Fabric Reinforced Polyester Based Composite}

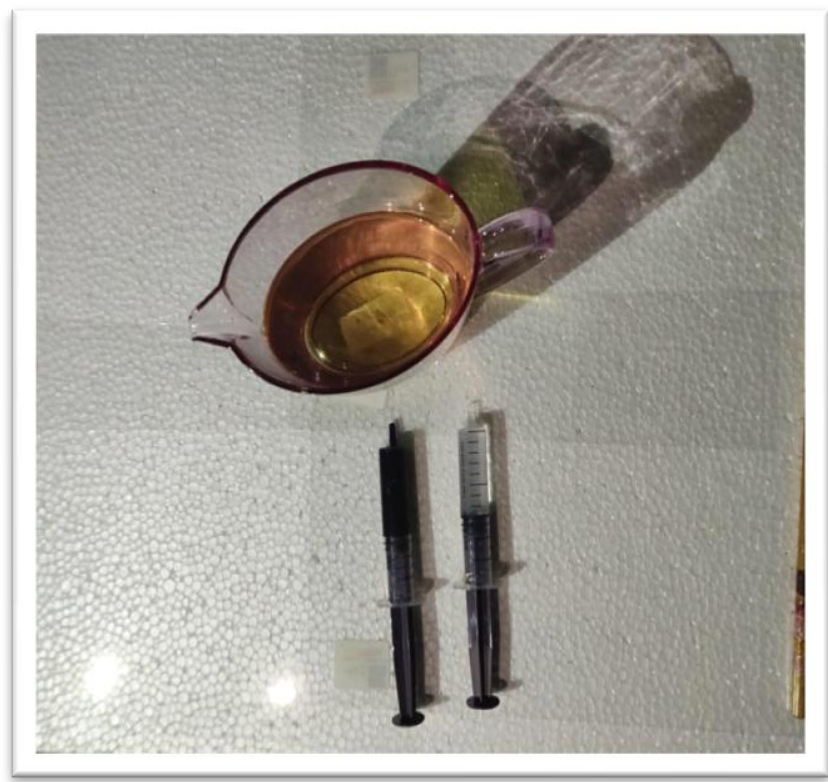

Fig.5. Beaker with isophthalic and syringes

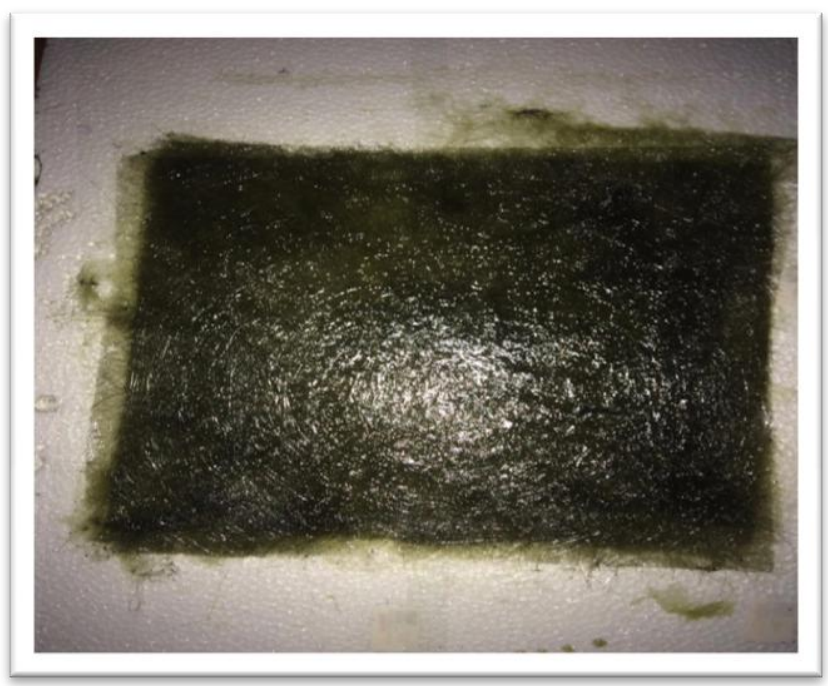

Fig.6. E-Glass Fabric Composite

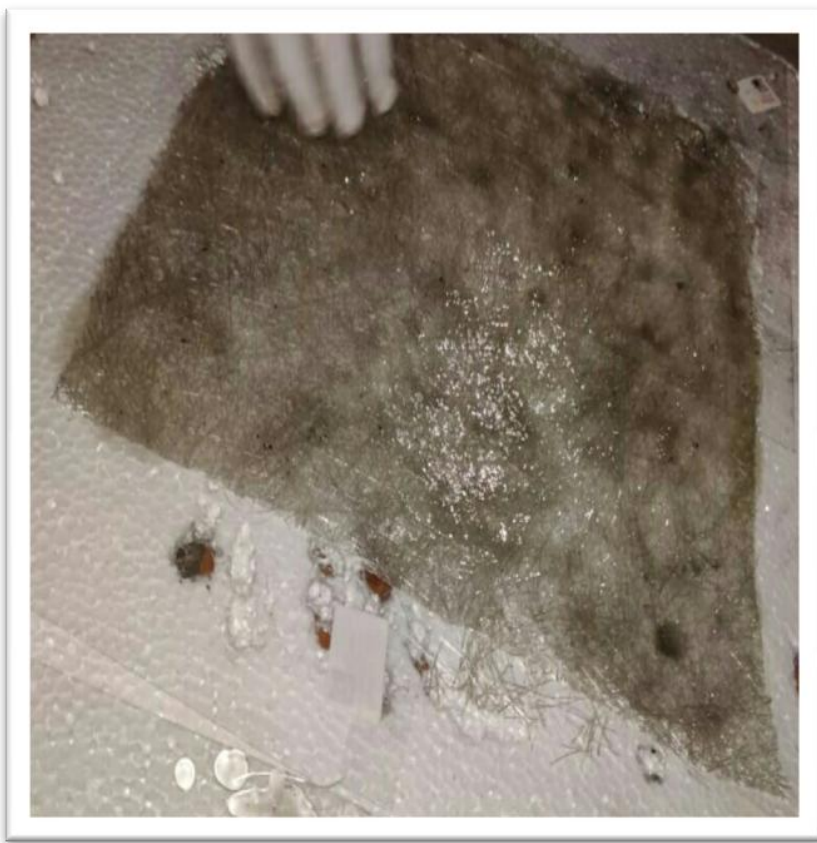

Fig.7. Flax Fabric Composite

\section{F. Experimental setup:}

Experimental procedures entirely performed as per the ASTM Standard. Mechanical test are performed as per the ASTM D 638, ASTM D 790, ASTM D 256 Standard Rate of burning is performed as per the ASTM D-635 standard. And SEM is performed as per the ASTM F1372 standard.

\section{RESULT AND DISCUSSION:}

G. Tensile testing:

Tensile testing was carried out as per the ASTM D638 Standards. Thegaugelengthofeachspecimenwas $50 \mathrm{~mm}$.The tests were conducted at $150^{\circ} \mathrm{C}$. The ASTM D638 process tensile properties as well as ultimate tensile strength, yield strength, elongation and Poisson's ratio. Generally testing machine used in tensile testing is the universal testing machine. The test procedurerequires placing the test specimen in the testing machine andexpanding it until it breaks. The elongation measurement is applied to calculate thestrain $(\varepsilon)$.The values of the tensile test is tabulated below in table 1 it could be determined that E-Glass Fibre has comparatively greater Mechanical properties than flax fabric, but the difference is negligible.

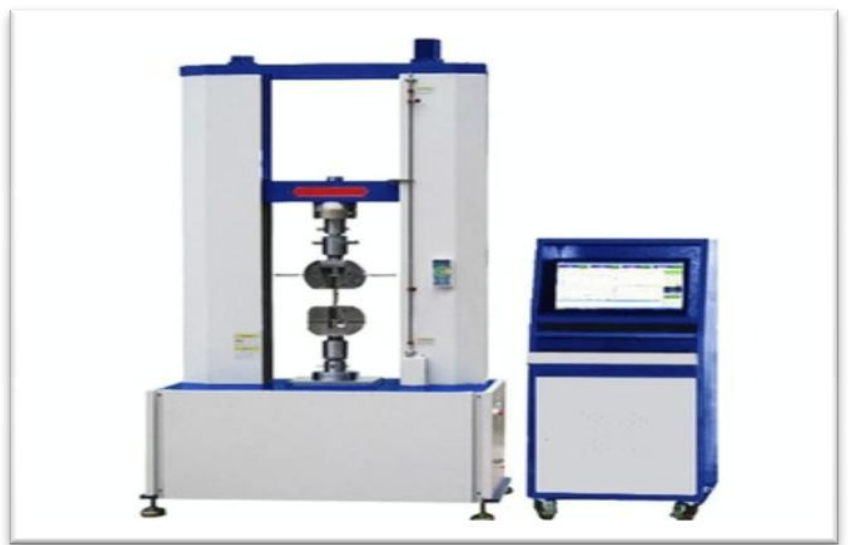

Fig.8. Universal Testing Machine

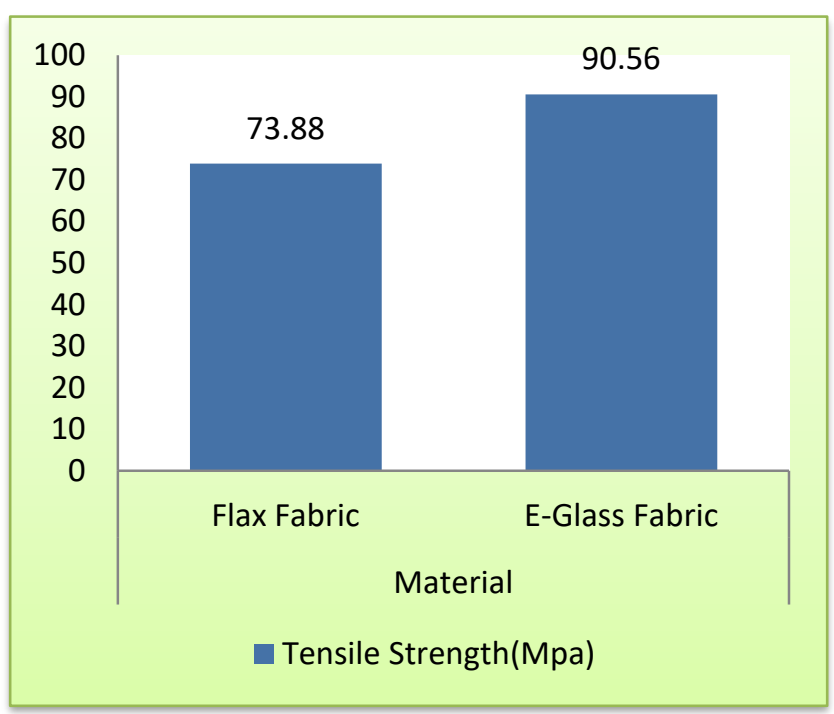

Fig.9. Comparison of specimens based on Tensile test

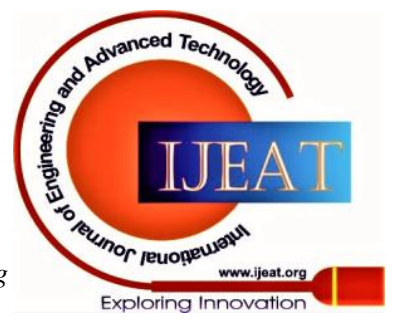


Establishment, Description and Equivalence of Flax Fabric Reinforced and E-Glass Fabric Reinforced Polyester Based Composite

\begin{tabular}{|c|c|c|}
\hline Test & \multicolumn{2}{|c|}{ Material } \\
\hline & Flax Fabric & E-Glass Fabric \\
\hline $\begin{array}{c}\text { Tensile } \\
\text { Strength(MPa) }\end{array}$ & 73.88 & 90.56 \\
\hline
\end{tabular}

Table 1: Tensile Strength Readings

\section{H. Flexural testing:}

Flexural testing was carried out as per the ASTM D256 Standards. The gauge length of each specimen was $50 \mathrm{~mm}$. The tests were conducted at ambient temperature. Flexural test determines the force needed to bend a beam of the material and govern the resistance to the stiffness of a material.Flexural test is carried out on a universal testing machine by a three-point or four-point bend fixture. The flexural test requires a particular test fixture and the specimen is placed on two supporting pins a set at a distance.Flexural testing measures the force required to bend a beam of material and determines the resistance to flexing or stiffness of a material. The values of the flexural test is tabulated below in table 2 it could be determined that E-Glass Fibre has comparatively greater Mechanical properties than flax fabric, but the difference is negligible.

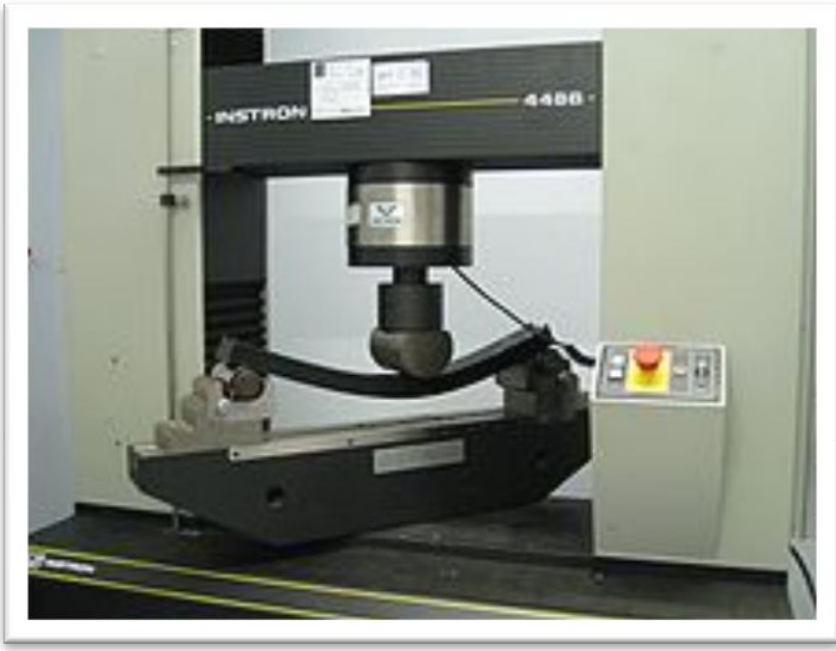

Fig.10. Universal Testing Machine (three-point fixture)

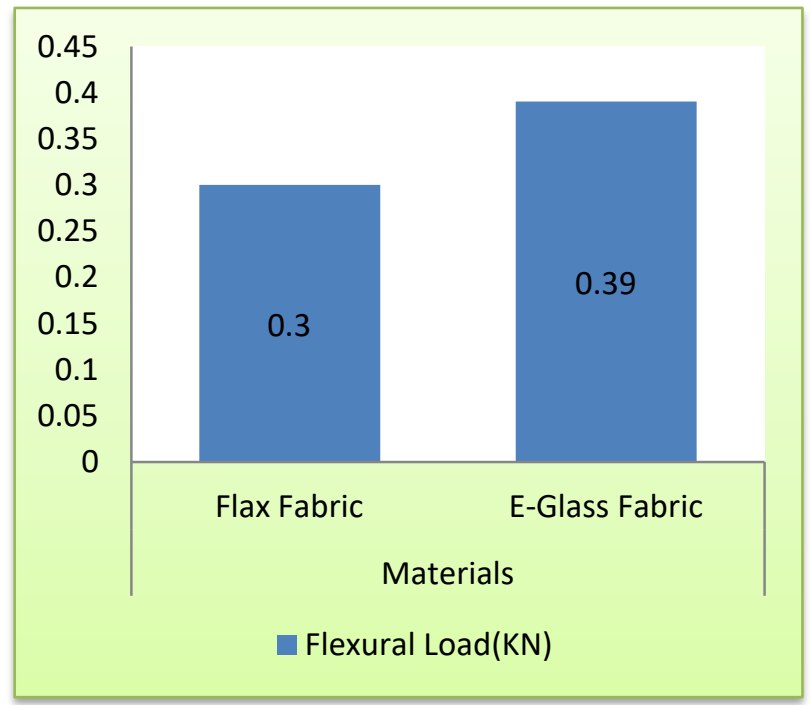

Fig.11. Comparison of specimens based on flexural test.

\begin{tabular}{|c|c|c|}
\hline Test & \multicolumn{2}{|c|}{ Materials } \\
\hline & Flax Fabric & E-Glass Fabric \\
\hline Flexural Load(KN) & 0.30 & 0.39 \\
\hline
\end{tabular}

Table 2: Flexural test readings

I. Impact Testing:

Impact testing was carried out as per the ASTM D790 Standards. The gauge length of eachspecimen was $50 \mathrm{~mm}$. The tests were conducted at ambient temperature. Impact test is used to decide the amount of energy wrapped up by a material during fracture. The wrapped energy used to determine the material toughness. Impact test also used to determine the material is brittle or ductile in nature. According to the ASTM standards the Izod impact strength test is used to determine the impact resistance of the material. The values of the impact test is tabulated below in table 3 it could be determined that E-Glass Fibre has comparatively greater Mechanical properties than flax fabric, but the difference is negligible.

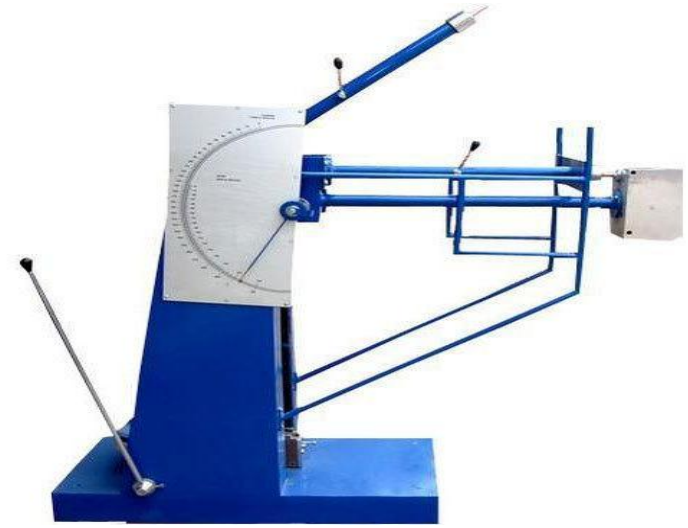

Fig.12. Izod Impact testing machine

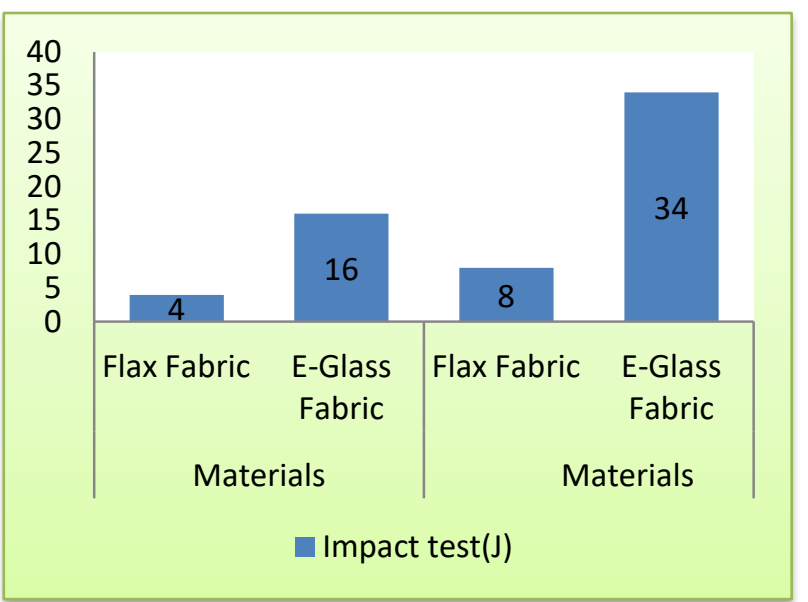

Fig.13. Comparison of specimens based on Impact test

\begin{tabular}{|c|c|c|}
\hline Test & \multicolumn{2}{|c|}{ Materials } \\
\hline & Flax Fabric & E-Glass Fabric \\
\hline Impact test(J) & 4,8 & 16,34 \\
\hline
\end{tabular}

Table 3: Impact Test readings

Published By:

Blue Eyes Intelligence Engineering

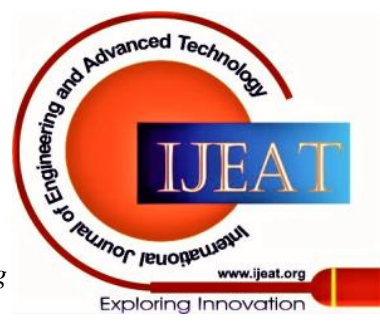




\section{Establishment, Description and Equivalence of Flax Fabric Reinforced and E-Glass Fabric Reinforced Polyester Based Composite}

\section{J. Surface Topology:}

Scanning Electron Microscope (SEM) is a kind of an electron microscope that produces pictures of a sample by scanning the surface within engaged light emission. The electrons communicate with atoms in the samples, creating different signals that contain data about the surface topography and composition of the sample. SEM can accomplish resolution better than 1 nanometer. At first the sample which is to be scanned is Gold coated in an encased chamber for one moment preceding directing SEM, this covering is done to improve electrical conductivity which facilitates the emerging process.

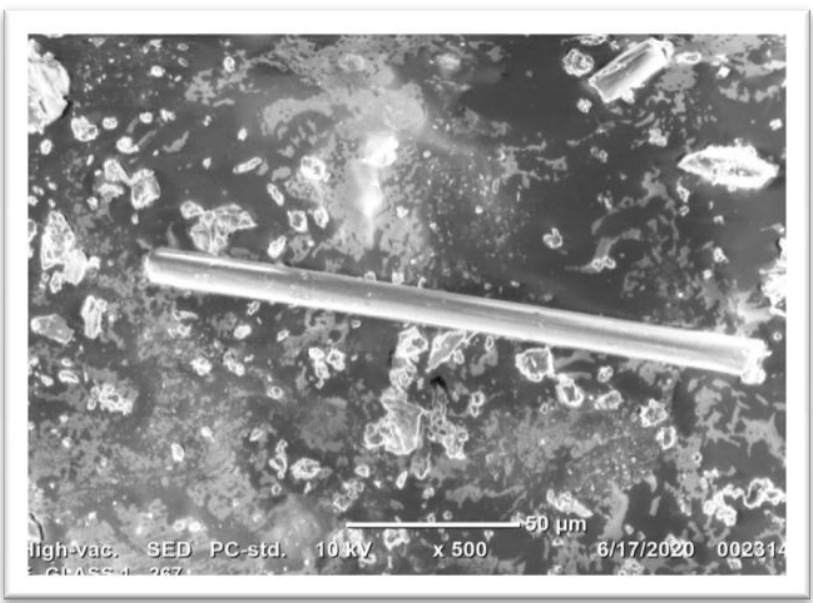

Fig.14.SEM image of E-Glass fabric before impact.

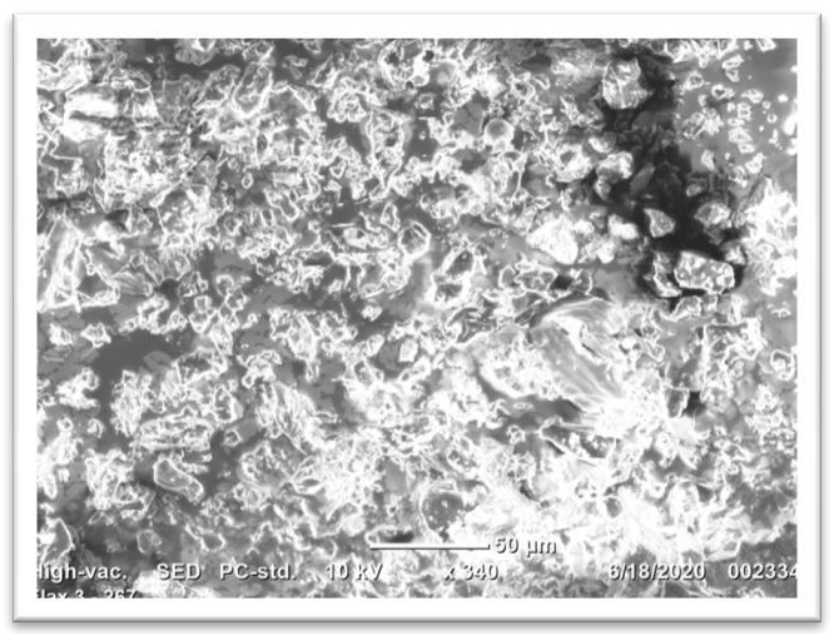

Fig.15. SEM image of Flax fabric before impact.

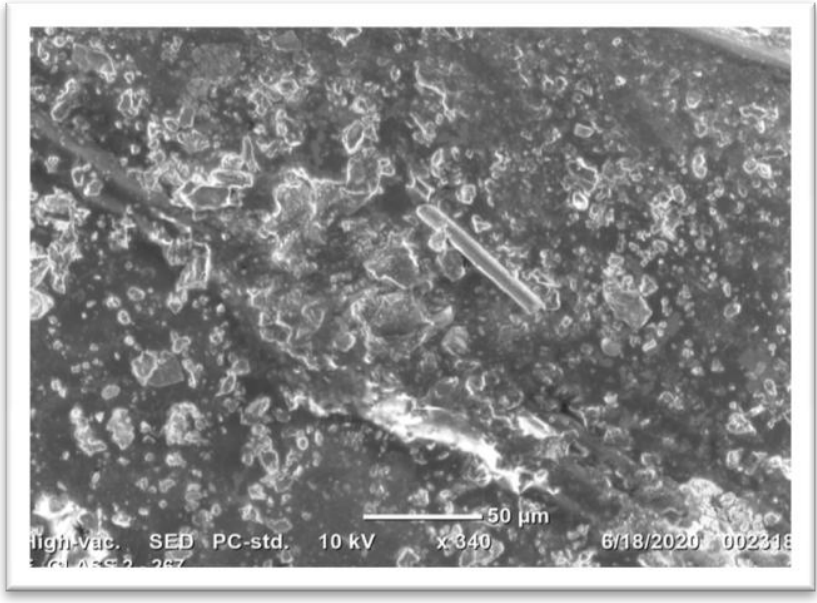

Fig.16. SEM image of E-Glass fabric after impact

Retrieval Number: 100.1/ijeat.A17551010120

DOI:10.35940/ijeat.A1755.1010120

Journal Website: www.ijeat.org

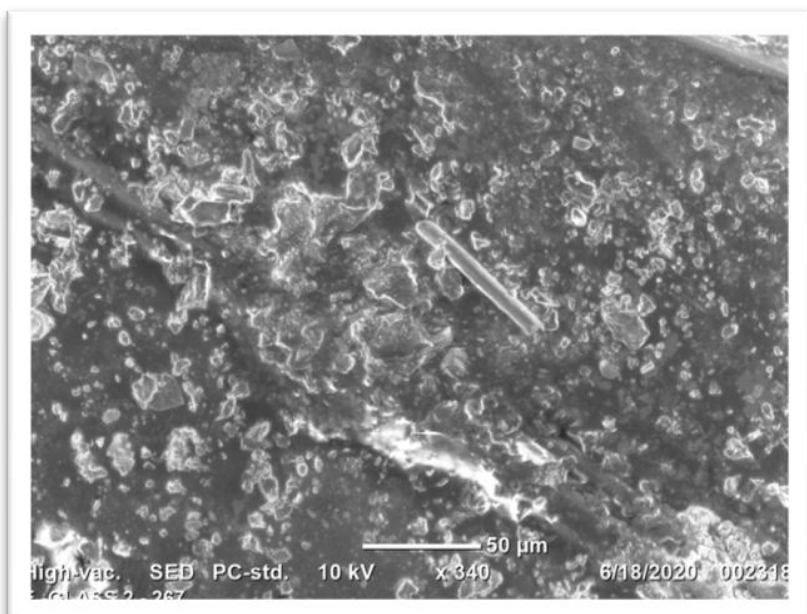

Fig.17. SEM of Flax fabric after impact

K. Rate of burning:

In rate of burning test as far as pace of consuming it is high in flax fabric followed by E-glass which influences the application and utilization of the material. Two samples were tested in each test.

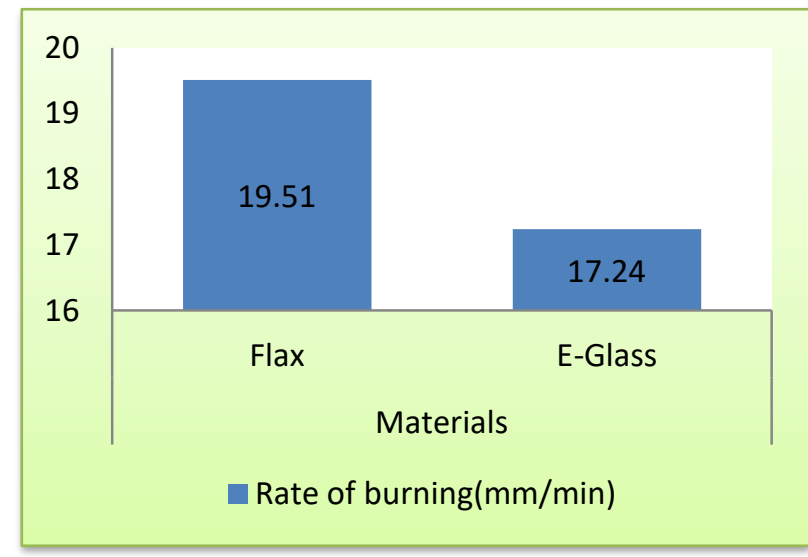

Fig.18. Comparison of specimens based on Rate of Burning

\begin{tabular}{|c|c|c|c|c|}
\hline Test & Standard & Unit & \multicolumn{2}{|c|}{ Result Obtained } \\
\hline & & & Flax & E-Glass \\
\hline $\begin{array}{c}\text { Rate of } \\
\text { burning }\end{array}$ & $\begin{array}{c}\text { ASTM } \\
\text { D635 }\end{array}$ & $\mathrm{mm} / \mathrm{min}$ & 19.51 & 17.24 \\
\hline
\end{tabular}

Table 4: Rate of Burning readings

\section{CONCLUSION:}

In a period of unpredictable environmental conditions, the utilization of natural fabrics as reinforcement has been proven as environmentally friendly in contrast to the conventional synthetic fabrics. Broad investigation has been made to analyse and compare the mechanical strength of Flax fabric and E-glass fabric reinforced polyester composites, with an outcome proving the following Inference.

Published By:

Blue Eyes Intelligence Engineering and Sciences Publication

(C) Convriaht: All riahts reserved.

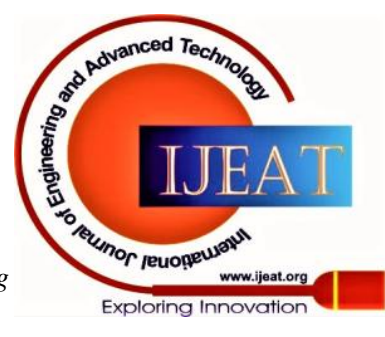




\section{Establishment, Description and Equivalence of Flax Fabric Reinforced and E-Glass Fabric Reinforced Polyester Based Composite}

- The mechanical properties of flax fabric composites are nearly at standard with the E-glass fabric in each perspective, however considering the ecological viewpoint it is wise to utilize natural based natural Flax fabric composites.

- Since both Flax fabric and E-glass fabric has nearly a similar hardness level it can supplant the E-glass Fabric in Hardness situated applications.

- SEM picture shows that Flax fabric composite has better structural integrity contrasted with E-Glass fabric composite even after the effect is made.

These results suggest that Flax fabric has huge potential in the making of Natural Fabric Composites. Such a material can find a lot of engineering as well as industrial application.

\section{REFERENCES:}

1. M. Janarthanan "Mechanical properties of flax fibers and their composites".

2. Layth Mohammed, M.N.M Ansari, Grace Pua, Mohammed Jawaid, M.Saiful Islam "A Review on Natural Fiber Reinforced Polymer Composite and Its Applications".

3. S.R. Benin,S. Kannan, Renjin J. Bright, A. Jacob Moses "A Review on mechanical characterization of polymer matrix composites and its effects reinforced with various natural fibres".

4. Miroslav Frydrych, Šťepán Hýsek, Ludmila Fridrichová, Su Le Van 2, Miroslav Herclík,Miroslava Pecho`ciaková, Hiep Le Chiand Petr Louda "Impact of Flax and Basalt Fibre Reinforcement onSelected Properties of Geopolymer Composites".

5. T. Srinivasan , G. Suresh , P. Ramu , V. Gokul Ram, M. Giresh , K. Arjun "Effect of water absorption of the mechanical behaviour of banana fiber reinforced IPN natural composites".

6. Manoj Kumar Singh and Sunny Zafar "Development and mechanical characterization of microwave-cured thermoplastic based natural fibre reinforced composites".

7. J.P. Torres, L.-J. Vandi, M. Veidt, M.T. Heitzmann "The mechanical properties of natural fibre composite laminates: a statistical study".

8. K.L. Pickering, M.G. Aruan Efendy, T.M. Le "A review of recent developments in natural fibre composites and their mechanical performance".

9. Kang Yang1, Sujun Wu1, Juan Guan1, Zhengzhong Shao2 \& Robert O. Ritchie "Enhancing the Mechanical Toughness of Epoxy-Resin Composites Using Natural Silk Reinforcements".

10. M. Fan , A. Naughton, J. Bregulla "Fire performance of natural fibre composites in construction".

\section{AUTHORS PROFILE:}

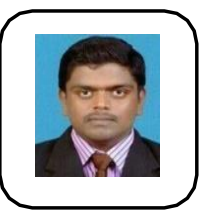

Mr. A. K. Arun Raja is working as an Assistant Professor in Mechanical Engineering Department in St. Joseph's Institute of Technology, OMR, Chennai, Tamil Nadu, India. He has a work experience of 7 years as assistant professor. He is currently pursuing his Ph.D. from Sathyabama University, OMR, Chennai, Tamil Nadu, India, in the topic "Bio Composites". Headstone total of 8publicationsincludingScopusand sci indexed journals. He has guided number of college students in completing their project on natural reinforced composites.

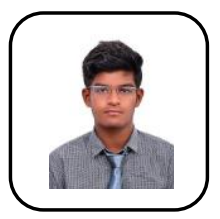

Mr. B. Sureshis a Final year student pursuing is B.E. degree in mechanical engineering in St. Joseph's Institute of Technology, OMR, Chennai, Tamil Nadu, India. He has done an academic project in "Design and Fabrication of Automatic Electro Hydraulic Jack". He also attended a lot of workshops and done In-plant trainings in notable companies such as Mitsubishi Heavy

Industries, Vellore.

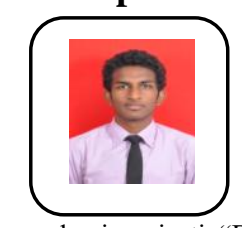

Mr. Shobhan Kumar is a final year student pursuing is B.E.degree in mechanical engineering in St. Joseph's Institute of Technology, OMR, Chennai, Tamil Nadu, India. He is a member of SAE India Southern Section. He has completed a project as intern trainee and has all done an academicprojectin“"DesignandFabrication".Hehasalsoattendedalotofwork shopsandin-plant of his department core industries.

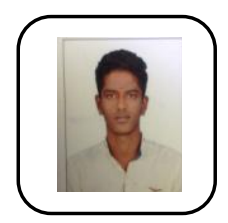

Mr. G. Priyadharshan is a final year student pursuing is B.E.degree in mechanical engineering in St. Joseph's Institute of Technology, OMR, Chennai, Tamil Nadu, India. He has completed a project as intern trainee and has all done an academic project in "Design and Fabrication of Automatic Electro Hydraulic Jack." He hasalsoatten deda lot of work shop sandin-plant of his department core industries.

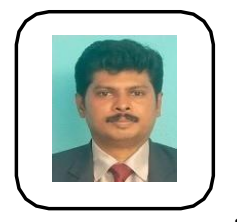

Dr. K. Arun Vasantha Geethan is working as a Professor and the Head Of the Department of Mechanical Engineering in St. Joseph's Institute of Technology, OMR, Chennai, Chennai, Tamil Nadu, India. He has a work experience of about 14 years in the field of teaching. He has done his awarded with Doctor of Philosophy in "Reverse supply chain management" as area of research. He has a total of 26 publications including SCI and Scopus Indexed Journals.

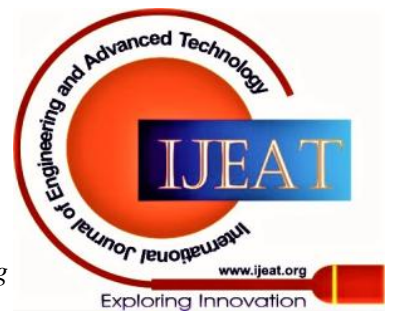

